\title{
Hydrophobic Variations of $\mathrm{N}$-Oxide Amphiphiles for Membrane Protein Manipulation: Importance of Non-hydrocarbon Groups in the Hydrophobic Portion
}

\author{
Prof. Pil Seok Chae ${ }^{[a]}$, Sadaf Aiman ${ }^{[a]}$, and Prof. Samuel H. Gellman ${ }^{[b]}$ \\ Pil Seok Chae: pchae@hanyang.ac.kr; Samuel H. Gellman: gellman@wisc.edu \\ [a]Department of Bionano Engineering, Hanyang University Ansan, 426-791 (Korea), Fax: (+) 81 \\ 314368146 \\ ${ }^{[b]}$ Department of Chemistry, University of Wisconsin-Madison 1101 University Avenue, Madison, \\ WI 53706 (USA)
}

\begin{abstract}
This study introduces several $N$-oxide amphiphiles evaluated for a large membrane protein assembly. Among these $N$-oxide amphiphiles, cholate-based agents (CAO and CAO-1) displayed the most favorable behaviors for membrane protein stabilization. This result raises the possibility that the identity and number of non-hydrocarbon groups present in the hydrophobic region plays a critical role in determining detergent properties.
\end{abstract}

\section{Keywords}

amphiphiles; membrane proteins; molecular design; non-hydrocarbon groups; stabilization

\begin{abstract}
Integral membrane proteins (IMPs) reside in lipid bilayers and play crucial roles in many cellular processes including signal transduction and material transfer between the cell cytoplasm and the environment. The fact that more than 50\% membrane proteins are targets for pharmaceutical agent under development underlines the importance of these biomacromolecules in the physiological cell state. ${ }^{[1]}$ Currently, more than 80,000 protein structures are available from the Protein Data Bank (PDB); however, the set of membrane proteins with known structure constitutes about $0.5 \%$ of the total number of known protein structures indicating the notorious difficulty in resolving membrane protein structure. ${ }^{[2]}$ This discrepancy between the number of known structures for membrane versus soluble proteins results from three major barriers associated with the former. First, membrane proteins are naturally present in low abundance as compared to soluble proteins; thus, it is difficult to obtain sufficient amount of protein for structural study. ${ }^{[3]}$ Second, membrane-bound macromolecules are highly unstable once removed from a lipid bilayer. In order to obtain high resolution crystal structures, membrane proteins must first be extracted from the native membranes using amphipathic compounds and retain its native structure during subsequent
\end{abstract}

Correspondence to: Pil Seok Chae, pchae@hanyang.ac.kr.

Supporting information for this article is available on the WWW under http://dx.doi.org/10.1002/asia.200xxxxxx. 
purification and crystallization processes. ${ }^{[4]}$ Because the detergent micelle environment significantly deviates from that of the native cell membrane, detergent-solubilized membrane proteins tend to denature and aggregate leading to a loss of function in an aqueous medium. ${ }^{[5]}$ Third, membrane proteins solubilized with detergents, called proteindetergent complexes (PDCs), have high conformational flexibility originating from both detergent molecules as well as membrane proteins. Conventional detergents consist of a flexible alkyl chain and a hydrophilic group such as $N$-oxide, glucose, or maltose as exemplified by lauryldimethylamine- $N$-oxide (LDAO), $n$-octyl- $\beta$-D-glucopyranoside (OG) and $n$-dodecyl- $\beta$-D-maltoside (DDM). Membrane proteins evolved to utilize a flexible loop to connect between two $\beta$-helixes or two domains. The multiple loops endow membrane proteins with high conformational flexibility for proper function. However, the high flexibility of PDCs could play an unfavorable role in protein crystal lattice formation requiring an ordered state. ${ }^{[6]}$ An ideal detergent should possess an ability to overcome these three barriers. The design of such a detergent molecule is very challenging because these multiple properties have to be inherent to a single detergent structure. More than 100 conventional detergents are commercially available but only a few are widely used for membrane protein research. ${ }^{[7]}$ Membrane proteins solubilized even in the most popular detergents are vulnerable to denaturation and aggregation. ${ }^{[5]}$ Thus, it is of great interest to develop novel classes of amphiphiles with enhanced properties in terms of membrane protein solubilization and stabilization.

Over the past a few decades, several types of amphiphiles have been devised to facilitate membrane protein study. Examples include tripod amphiphiles (TPAs), ${ }^{\left[{ }^{[a, b]}\right.}$ hemifluorinated surfactants (HFSs), ${ }^{[8 \mathrm{c}-\mathrm{e}]}$ peptide-based amphipathic oligomers, ${ }^{\left[{ }^{[\mathrm{f}}-\mathrm{h}\right]}$ cholate or cholesterolbased amphiphiles, ${ }^{[8 i-\mathrm{k}]}$ and rigid hydrophobic group-bearing amphiphiles. ${ }^{[81, \mathrm{~m}]}$ Amphiphilic polymers such as amphipols (Apols), ${ }^{[8 \mathrm{~d}, \mathrm{n}]}$ nanodiscs (NDs), ${ }^{[8 \mathrm{~d}, \mathrm{o}]}$ and lipodisqs ${ }^{[8 \mathrm{p}]}$ are innovative approaches to overcome the limitation of amphiphiles with low molecular weights. Recently, maltose-neopentyl glycol (MNG) ${ }^{[8 \mathrm{e}, \mathrm{q}, \mathrm{r}]}$ and glucose-neopentyl glycol (GNG) amphiphiles ${ }^{[8 \mathrm{~s}]}$ were shown to be extremely promising in providing highresolution crystal structures of more than 10 membrane proteins including several G-protein coupled receptors (GPCRs). ${ }^{[9]}$ Recently developed cholate-based facial amphiphiles (FAs) were shown to be promising in membrane protein crystallization as well, ${ }^{[10]}$ all emphasizing the important role of new detergents in membrane protein structure study. Despite a wealth of studies on conventional detergents and novel agents, information on detergent structureproperty relationships is seriously limited. Finding such relationships will have a great impact on membrane protein research because these structure-property relationships not only will provide useful guidelines for the future development of novel amphipathic molecules but will also give insight in selecting detergent candidates best-suited for a target membrane protein.

Detergents are most generally classified into three categories depending on the electronic structures of the hydrophilic groups: ionic, zwitterionic, and nonionic detergents. Nonionic agents, in general, are preferably used to ionic and zwitterionic detergents because the former are superior to the latter with regard to membrane protein stabilization. ${ }^{[4]}$ However, it is notable that zwitterionic detergents are usually better than nonionic detergents in terms 
of membrane protein solubilization. Thus, it is generally accepted that there is a compromise in detergent properties toward membrane protein manipulation; a strong solubilizing agent is known to be a poor stabilizing compound for membrane protein study. ${ }^{[4 a, 8 f]}$ Two zwitterionic detergent representatives with a flexible alkyl chain include Anzergent 3-12 with a sulfobetaine head group and LDAO with a $N$-oxide head group (Scheme 1). Between these two, LDAO is more widely useful for membrane protein structural study via $\mathrm{x}$-ray crystallography and nuclear magnetic resonance (NMR) spectroscopy. ${ }^{[4 a, 11]}$ The wide use of this agent is likely attributed to the formation of small protein-detergent complexes (PDCs). It is generally accepted that small PDC size serves a favorable role in protein crystal formation as the large hydrophilic surface area of membrane proteins displayed by small complexes would facilitate the crystallization process. ${ }^{[4]}$ Small PDC size is also a favorable attribute in NMR-based structure studies because of the reduced rotational correlation time of an incorporated protein. On the other hand, cholate-based zwitterionic detergents with a sulfobetaine head group, 3-[(3-cholamindopropyl) dimethylammonio]-1-propanesulfonate (CHAPS) and 3-[(3-cholamidopropyl) dimethylammonio]-2-hydroxy-1-propanesulfonate (CHAPSO), are known as mild detergents because they have often showed a non-denaturing property during the solubilization process of fragile membrane proteins (Scheme 1). ${ }^{[12]}$ These agents have an interesting hydrophobic group, a multi-fused ring system bearing three hydroxyl groups at $\mathrm{C} 3, \mathrm{C} 7$ and $\mathrm{C} 12$. We envision that this structural uniqueness is the origin of its favorable membrane protein stabilization efficacy; thus, it is a logical extension to design $N$-oxide counterparts of these amphiphiles. The resulting agents are expected to possess combined characteristics including the merit of the small head group and the mildness of cholate-based amphiphiles. In this study, we prepared cholate-, deoxycholate-, and lithocholate-based $N$-oxide amphiphiles. Dipod amphiphiles (DPAs) with two rings were also prepared for comparison. These structurally related compounds were evaluated for the study of the Rhodobacter capsulatus photosynthetic superassembly. The results show that cholate- or deoxycholate-based $N$-oxide amphiphiles displayed favorable behavior in the superassembly manipulation as compared to DPAs and conventional detergents (LDAO and DDM). More importantly, systematic variation in the amphiphile structures enabled us to suggest a structure-property relationship that will serve as a useful guideline for the future design of novel classes of amphiphiles.

The hydrophobic variations of $N$-oxide amphiphiles are illustrated in several examples, including three dipod amphiphiles (DPA-1, DPA-2, and DPA-3) and cholate-, deoxycholate-, and lithocholate-based amphiphiles (designated CAO, DCAO and LCAO, respectively) (Scheme 2). DPAs share an $N$-oxide head group but vary in their hydrophobic groups; DPA-1 has cyclopentyl and cycloheptyl rings while DPA-2 and DPA-3 bear two benzene and cyclohexane rings, respectively. On the other hand, CAO, DCAO, and LCAO are unique in having a multi-fused ring-based hydrophobic group bearing a different number of hydroxyl groups. In order to facilitate the synthesis of multi-fused ring-bearing amphiphiles, we utilized three commercially available acid derivatives with a various number of hydroxyl groups: cholic acid, deoxycholic acid, and lithocholic acid. We prepared all $N$-oxide amphiphiles in high synthetic yield (>85\%) by straightforward synthetic methods such as amide coupling and oxidation with $m$-chloroperbenzoic acid $(m$-CPBA) (see Supporting Information for details). 
All of the amphiphiles except for LCAO and DCAO were water-soluble up to $10 \mathrm{wt} \%$.

LCAO was insoluble in water and thus was not studied further. DCAO was initially soluble at approximately $1.0 \%$ but tended to form a hydrogel with time at concentrations greater than $0.3 \%$. Critical micelle concentration (CMC) values were estimated using the hydrophobic fluorescent dye, diphenyhexatriene (DPH). ${ }^{[13]}$ Data for the new agents along with DDM and LDAO are presented in Table 1. The CMC values of DPAs were found to have a large variation depending on the hydrophobic groups. DPA-2 with two benzene rings was estimated to be highest ( $77.5 \mathrm{mM} ; \sim 2.5 \mathrm{wt} \%)$ while DPA-3 with two cyclohexane rings was estimated to be lowest $(\sim 4.9 \mathrm{mM} ; \sim 0.17 \mathrm{wt} \%)$. DPA-1 was estimated to have intermediate $\mathrm{CMC}$ values ( $13 \mathrm{mM} ; \sim 0.42 \mathrm{wt} \%)$. The rather large CMC values of DPA-2 relative to that of DPA-3 is likely due to the polar character of the benzene ring relative to the cyclohexane ring, thus having less propensity for self-association. On the other hand, DCAO and CAO with two and three hydroxyl groups in the lipophilic region, respectively, showed $\sim 8$ times difference in their CMC values $(\sim 1.0 \mathrm{mM}$ and $\sim 8.3 \mathrm{mM}$, respectively). The CMC value of CAO was similar to that of CHAPS $(\sim 8.0 \mathrm{mM}),{ }^{[12 \mathrm{a}, \mathrm{b}]}$ consistent with the general notion that a hydrophobic group is the main factor in detergent self-assembly behavior.

The photosynthetic superassembly of $R$. capsulatus was employed to evaluate the new $N$ oxide amphiphiles and conventional detergents (LDAO and DDM). The native form of the superassembly consists of three components: the labile light harvesting complex I (LHI), the resilient reaction center complex (RC), and the most robust light harvesting complex II (LHII). ${ }^{[8 b]}$ The superassembly used for this study doesn't contain the LHII portion as we removed this portion via genetic engineering. ${ }^{[14]}$ The resulting LHI-RC complex contains dozens of protein subunits with five different components, making it challenging to preserve its native quaternary structure. ${ }^{[8 b]}$ Mild detergents (e.g. DDM) maintain the native conformation of the LHI-RC complex while detergents of intermediate strength (e.g. LDAO and Triton X-100) destroy most of the LHI complex leaving the RC complex intact. The use of harsh detergents such as sodium dodecyl sulfate (SDS) destructs both LHI and RC complex structures. Thus, the LHI-RC complex is an excellent system to classify a wide range of detergents according to their strength. The presence of embedded cofactors including bacteriochlorophylls and carotenoids in the complexes gives rise to a well-featured UV-Vis absorption spectrum, which facilitates the assessment of protein integrity for a set of detergents via optical spectrophotometry. The native conformation of the protein is represented by a very strong peak at $875 \mathrm{~nm}$ in the absorption spectrum while the intact RC but denatured LHI, or denatured LHI and RC, produces rather intense peaks at $\sim 800 \mathrm{~nm}$ and $\sim 760 \mathrm{~nm}$, respectively. A previous study showed that DDM was the most promising conventional detergent for the solubilization and stabilization of the superassembly, ${ }^{[8 \mathrm{~b}]}$ which is in good agreement with the wide use of this agent in membrane protein science. ${ }^{[15]}$ In contrast, LDAO was shown to destroy the structural integrity of LHI-RC complexes. As such, we chose these two agents as assay control agents.

For superassembly solubilization, the intracytoplasmic $R$. capsulatus membranes enriched in LHI-RC complex were treated with 10xCMC individual new agents except for DPA-2;

DPA-2 was tested at $2 \mathrm{xCMC}$ based on its high CMC value. On the other hand, conventional 
detergents (LDAO and DDM) were used at 50xCMC due to the small CMC value in terms of $\mathrm{wt} \%$. The solubilized protein portion and insolubilized portion containing cellular debris and insolubilized membranes were separated via ultracentrifugation and isolated as the supernatant and pellet, respectively. The absorption spectra of these two portions were taken to assess detergent efficacy on protein solubilization and stabilization (Figs. 1a \& S1). The detergent-solubilized protein samples were then subjected to a metal affinity column chromatography and eluted with elution buffer containing 1M imidazole and 1xCMC individual detergents for purification. The UV-Vis spectra of the resulting protein samples were taken to investigate the integrity of detergent-purified LHI-RC complexes (Figs. 1b \& S2). Consistent with previous results, LDAO extracted the complexes almost quantitatively (Fig. S1 \& Table 1), with the native protein conformation being mostly destroyed during the solubilization and purification processes (Fig. 1a, b). ${ }^{[8 \mathrm{~b}]}$ A similar trend was observed for DPA-1 while DPA-3 displayed somewhat different behavior. DPA-3 solubilized the LHIRC complexes as efficiently as DPA-1 (Fig. S1; 95-100 \%), but the extent of protein degradation observed for DPA-3 was much less than those observed for DPA-1 and LDAO (Fig. S2). The enhanced stabilizing characteristics of DPA-3 relative to DPA-1 were also evident in the absorption spectra of the purified proteins (Fig. S2b). On the other hand, DPA-2 with two phenyl groups failed to efficiently extract the complexes $(\sim 15 \%)$ and most of the extracted complexes underwent significant structural degradation. In contrast, the behaviors of CAO and DCAO significantly deviated from those of the DPAs and LDAO despite the fact that they share the $\mathrm{N}$-oxide head group; $\mathrm{CAO}$ and DCAO were somewhat inferior to the DPAs and LDAO for the extraction of the LHI-RC complexes ( $30 \%$ and $\sim 70 \%$, respectively), but the native structure of the complexes solubilized and purified in these agents was fully retained as effectively as DDM (Fig. 1a, b). Under these conditions, DCAO did not form hydrogel during the course of experiment.

The favorable properties of $\mathrm{CAO}$ and DCAO in terms of membrane protein stabilization prompted us to further evaluate their ability to stabilize the superassembly as a function of time. DDM-purified samples were diluted with solutions containing individual detergents. The final detergent concentration in each sample was $\mathrm{CMC}+0.04 \mathrm{wt} \%$ and the dilution made the residual DDM concentration far below its CMC (0.0004 wt \%). Protein stability was monitored over time at room temperature by measuring absorbance ratio (A875/A680) (absorption at $680 \mathrm{~nm}$ is due to the oxidation of bacteriochlorophyll dissociated from LHI upon denaturation). ${ }^{[\mathrm{bb}]}$ The CAO- and DCAO-solubilized superassemblies were more stable than DDM-solubilized protein with the best performance observed for CAO (Fig. 1c). When we increased the detergent concentration to $\mathrm{CMC}+1.0 \mathrm{wt} \%$, the efficacy difference between CAO and DDM was more prominent (Fig. 1d). Of note, we could not evaluate DCAO in this long-term stability of the superassembly due to its high tendency to form a hydrogel at this high concentration.

As an effort to enhance detergent properties and to exclude the water-solubility issue associated with DCAO, we prepared CAO and DCAO analogues designated as CAO-1, DCAO-1, and DCAO-2 (Scheme 2). These agents share the same hydrophobic groups as their parent compounds (CAO and DCAO, respectively), but vary in the hydrophilic group. CAO-1 and DCAO-1 have an additional methyl group on the amide nitrogen while 
DCAO-2, a constitutional isomer of DCAO-1, contains an ethyl group on the amide nitrogen with the chain length between the amide and the head group shorter by one carbon than the other CAO and DCAO derivatives. DCAO-1 showed limited solubility in water while DCAO-2 was water-soluble well up to $5 \mathrm{wt} \%$. Neither agent formed a hydrogel similar to DCAO. The CMC values were determined for CAO-1 ( 7.2 mM; $\sim 0.38$ wt $\%)$ and DCAO-2 $(\sim 1.1 \mathrm{mM} ; \sim 0.056 \mathrm{wt} \%)$, which are similar to those of their parent CAO and DCAO compounds, respectively (Table 1). When these new derivatives were evaluated with LHI$\mathrm{RC}$ complexes, the agents displayed somewhat different behaviors from their parent compounds in terms of protein solubilization efficiency (Fig. S3); CAO-1 was rather inferior to its original ( $20 \%$ vs. $30 \%$ ) while DCAO-2 was superior to DCAO (80\% vs. $70 \%)$. However, we did not find any appreciable difference in the protein stabilization efficacy between the derivatives and the respective originals; all of the cholate and deoxycholatebased agents well preserved the native conformation of the superassembly during the protein solubilization and purification processes (Fig. 2a, b). When we evaluated these agents for superassembly long-term stability, we still only observed a minimal difference between the new derivatives (CAO-1 and DCAO-2) and their respective originals (CAO and DCAO). However, we could discriminate detergent efficacy between the cholate- and deoxycholatebased amphiphiles, as the cholate-based agents were clearly superior to the deoxycholatebased compounds. In a comparison with DDM, it is notable that DCAO-2 slightly outperformed this conventional detergent at low and high detergent concentrations (CMC + $0.04 \mathrm{wt} \%$ and $\mathrm{CMC}+1.0 \mathrm{wt} \%$, respectively). In addition, CAO- 1 was clearly superior to DDM at these concentrations as was CAO (Fig. 2c, d). We did not include DCAO in this long-term stability evaluation because this agent tends to form a hydrogel during long-term storage.

With the exception of DDM, all amphiphiles investigated in the current study share $\mathrm{N}$-oxide as the hydrophilic group but vary in their hydrophobic portions ranging from a $\mathrm{C} 12$ alkyl chain (LDAO), to two-ring systems (DPA-1, DPA-2, and DPA-3), to multiple-fused ring systems with a various number of hydroxyl groups (CAO, CAO-1, DCAO, and DCAO-2). When these $\mathrm{N}$-oxide amphiphiles were evaluated for the solubilization and stabilization of LHI-RC complexes, they displayed a large variation of behavior depending on the hydrophobic group architecture. This result indicates the prominent roles of the hydrophobic groups in membrane protein manipulation. LDAO and the DPAs, with the exception of DPA-2, appeared to quantitatively solubilize the LHI-RC complexes from the membrane, although most of LHI-RC complexes solubilized with these agents lost their native conformation. Among the three DPAs, DPA-3-solubilized complexes were the least destabilized, indicating that this agent may find utility in other membrane protein cases with more robust character. In contrast, although displaying less efficiency in solubilizing LHIRC complexes, the cholate- and deoxycholate-based amphiphiles were much more effective than the DPAs and LDAO in maintaining the native conformation of the solubilized superassembly. A substantial difference between cholate- and deoxycholate-based amphiphiles was also found in the superassembly solubilization and long-term stability experiments; the deoxycholate-based amphiphiles (DCAO and DCAO-2) were superior to the cholate-based amphiphiles (CAO and CAO-1) in the protein solubilization efficiency but inferior to the latter in the long-term protein stabilization efficacy. It is notable that DCAO-2 
displayed favorable behavior in superassembly solubilization and stabilization. The two cholate-based amphiphiles (CAO and CAO-1) are especially promising for the stabilization of complexes, although their solubilization efficiencies were inferior to DDM.

The favorable behaviors of cholate- and deoxycholate-based $N$-oxide amphiphiles observed for the superassembly manipulation can be first traced to the presence of the multiple hydroxyl groups in the lipophilic region and second to the facial orientation of polar groups $^{[16]}$ and/or the multi-fused ring system. Among these features, the first is particularly interesting because some recently developed novel agents contain similar structure motifs. For instance, the design of some short peptides has multiple amide groups over the lipophilic backbone while GLCs/GDN contains an ether-type group at the end of the hydrophobic groups (Fig. S4). ${ }^{[8 \mathrm{~g}, 1]}$ Tandem facial amphiphiles (TFAs) bear two amide linkages at the center region of the hydrophobic moiety. ${ }^{[8 j]}$ These functional groups (i.e., amide and ether groups) are polar relative to the hydrocarbons; thus, these non-hydrocarbon groupcontaining hydrophobic parts are less hydrophobic than their counterparts with no such groups, thus being relatively lipophobic. A similar characteristic can be also found in HFSs with a hemifluorinated alkyl chain that is lipophobic but hydrophobic. ${ }^{[8 c, d]}$ Of note, all the novel agents mentioned above share the presence of the lipophobic moieties (e.g., alcohol, ether, amide, or fluorine atoms) in their hydrophobic regions, although those lipophobic groups have a significant variation in their lipophobicities. All of these agents were shown to be mild enough to retain the native structures of various membrane proteins.

We believe that the presence of such lipophobic groups in the hydrophobic region modulates the interaction of these amphiphiles with the hydrophobic surface of membrane proteins. Since detergent-protein interaction strength should be modulated for the best performance, it is likely that there is an optimum range for the number of lipophobic groups. This optimal number would be dependent on various factors including the lipophobic group being used, the location of the group within the hydrophobic region, the nature of the target protein, and the type of protein manipulation being conducted. Some of this dependence was seen in our studies; the cholate-based amphiphiles with three hydroxyls behaved most favorably for protein stabilization while the deoxycholate-based amphiphiles with two hydroxyls performed better than the cholate-based amphiphiles in superassembly solubilization. A previous studies also supports this speculation; F4-HF-MNG with four fluorine atoms on the benzene ring was superior to F12-HF-MNG with 12 fluorine atoms for the stabilization of the same complexes. ${ }^{[8 \mathrm{e}]} \mathrm{A}$ similar phenomenon was observed in the comparative study of HFSs to FSs; HFSs with an alkyl tip, thus containing less fluorine atoms, were superior to fully-fluorinated HFs with regard to membrane protein stabilization. ${ }^{[8 \mathrm{~d}]}$

The zwitterionic class of detergents (e.g. LDAO) is known to be rather harsh in membrane protein manipulation. ${ }^{[8 f]}$ Thus, nonionic detergents such as OG and DDM have been favorably used for membrane protein research. Interestingly, CHAPS having a zwitterionic sulfobetaine head group often displayed favorable behaviors as much as non-ionic detergents in membrane protein stabilization, thus being widely used as an additive in membrane protein manipulation. ${ }^{[12]}$ A similar result was observed in our previous study (unpublished data) where CHAPS was shown to extract LHI-RC complexes without structural degradation although the solubilization yield was rather low ( $50 \%)$, which 
brought our attention to their structural origin for this favorable behavior. In spite of their interesting properties, CHAPS analogues have been rarely explored. Furthermore, systematic investigation and thorough data analysis have rarely been conducted to pinpoint the structural traits of this class that are responsible for such favorable behaviors. Our current study along with others raises the possibility that the presence and number of relatively lipophobic non-hydrocarbon groups such as alcohol, ether, or amide in the lipophilic region plays a crucial role in determining detergent properties, although more extensive studies are necessary to generalize such relationships to other membrane protein systems. This structure-property relationship will provide useful guidelines for the future design of novel amphiphiles. In addition, CAOs and DCAOs may find utility in another arena such as cell-free translation and bicelle preparation considering that HFSs have been successfully used in producing membrane proteins in a cell-free system ${ }^{[8 \mathrm{~d}]}$ and CHAPS or CHAPSO has been used to cap patches of lipid bilayer in bicelle preparation. ${ }^{[17]}$

In summary, we prepared and evaluated hydrophobic variations of $N$-oxide amphiphiles using fragile LHI-RC superassembly complexes. The cholate-based agents were most outstanding in the protein stabilization whereas the deoxycholate-based amphiphiles found utility in the solubilization and stabilization of the superassembly, indicating that these amphiphiles could serve as promising alternatives to conventional detergents in membrane protein research. More importantly, our results allow us to suggest the detergent structureproperty relationship with respect to the effect of a non-hydrocarbon group present in the lipophilic regions on membrane protein solubilization and stabilization.

\section{Experimental Section}

Details for the amphiphile synthesis and characterization as well as membrane protein solubilization and stabilization may be found in the Supporting Information.

\section{Supplementary Material}

Refer to Web version on PubMed Central for supplementary material.

\section{Acknowledgments}

The National Research Foundation of Korea (NRF) funded by the Korea government (MSIP) (grant number 2008-0061891 and 2012R1A1A1040964 to P.S.C.) and a NIH grant (P01 GM75913 to S.H.G.) supported this work. We thank Philip Laible (Argonne National Laboratory, IL, USA) for supplying membrane preparations from R. capsulatus.

\section{References}

1. Overington JP, Al-Lazikani B, Hopkins AL. Nat Rev Drug Discovery. 2006; 5:993-996.

2. Lacapere JJ, Pebay-Peyroula E, Neumann JM, Etchebest C. Trends Biochem Sci. 2007; 32:259-270. [PubMed: 17481903]

3. Junge F, Schneider B, Reckel S, Schwarz D, Dotsch V, Bernhard F. Cell Mol Life Sci. 2008; 65:1729-1755. [PubMed: 18408885]

4. a) Prive GG. Methods. 2007; 41:388-397. [PubMed: 17367711] b) Zhang Q, Tao H, Hong WX. Methods. 2011; 55:318-323. [PubMed: 21958988]

5. a) Garavito RM, Ferguson-Miller S. J Biol Chem. 2001; 276:32403-32406. [PubMed: 11432878] b) Bowie JU. Curr Opin Struct Biol. 2001; 11:397-402. [PubMed: 11495729] c) Serrano-Vega MJ, 
Magnani F, Shibata Y, Tate CG. Proc Natl Acad Sci U S A. 2008; 105:877-882. [PubMed: 18192400]

6. Chae PS, Laible PD, Gellman SH. Mol Bio Syst. 2010; 6:86-94.

7. a) White SH, Wimley WC. Annu Rev Biophys Biomol Struct. 1999; 28:319-365. [PubMed: 10410805] b) Moller JV, le Maire J. J Biol Chem. 1993; 268:18659-18672. [PubMed: 8395515]

8. a) McQuade, Quinn MA, Yu SM, Polans AS, Krebs MP, Gellman SH. Angew Chem Int Ed. 2000; 39:758-761.b) Chae PS, Wander MJ, Bowling AP, Laible PD, Gellman SH. Chem Bio Chem. 2008; 9:1706-1709.c) Breyton C, Chabaud E, Chaudier Y, Pucci B, Popot JL. FEBS Lett. 2004; 564:312-318. [PubMed: 15111115] d) Popot JL, et al. Annu Rev Biophys. 2011; 40:379-408. [PubMed: 21545287] e) Cho KH, Byrne B, Chae PS. Chem Bio Chem. 2013; 14:452-455.f) McGregor CL, Chen L, Pomroy NC, Hwang P, Go S, Chakrabartty A, Privé GG. Nat Biotechnol. 2003; 21:171-176. [PubMed: 12524549] g) Zhao X, Nagai Y, Reeves PJ, Kiley P, Khorana HG, Zhang S. Proc Natl Acad Sci U S A. 2006; 103:17707-17712. [PubMed: 17098868] h) Tao H, Lee SC, Moeller A, Roy RS, Siu FY, Zimmermann J, Stevens RC, Potter CS, Carragher B, Zhang Q. Nat Methods. 2013; 10:759-761. [PubMed: 23817067] i) Zhang Q, Ma X, Ward A, Hong WX, Jaakola VP, Stevens RC, Finn MG, Chang G. Angew Chem Int Ed. 2007; 46:7023-7025.j) Chae PS, Gotfryd K, Pacyna J, Miercke LJW, Rasmussen SGF, Robbins RA, Rana RR, Loland CJ, Kobilka B, Stroud R, Byrne B, Gether U, Gellman SH. J Am Chem Soc. 2010; 132:16750-16752. [PubMed: 21049926] k) Howell SC, Mittal R, Huang L, Travis B, Breyer RM, Sanders CR. Biochemistry. 2010; 49:9572-9583. [PubMed: 20919740] 1) Chae PS, Rasmussen SGF, Rana RR, Gotfryd K, Kruse AC, Nurva S, Gether U, Guan L, Loland CJ, Byrne B, Kobilka BK, Gellman SH. Chem-Eur J. 2012; 18:9485-9490. [PubMed: 22730191] m) Hovers J, Potschies M, Polidori A, Pucci B, Raynal S, Bonneté F, Serrano-Vega MJ, Tate CG, Picot D, Pierre Y, Popot J-L, Nehmé R, Bidet M, Mus-Veteau I, Busskamp H, Jung K-H, Marx A, Timmins PA, Welte W. Mol Membr Biol. 2011; 28:170-180.n) Tribet C, Audebert R, Popot JL. Proc Natl Acad Sci U S A. 1996; 93:15047-15050. [PubMed: 8986761] o) Nath A, Atkins WM, Sligar SG. Biochemistry. 2007; 46:2059-2069. [PubMed: 17263563] p) Orwick-Rydmark M, Lovett JE, Graziadei A, Lindholm L, Hicks MR, Watts A. Nano Lett. 2012; 12:4687-4692. [PubMed: 22827450] q) Chae PS, Rasmussen SGF, Rana RR, Gotfryd K, Chandra R, Goren MA, Kruse AC, Nurva S, Loland CJ, Pierre Y, Drew D, Popot JL, Picot D, Fox BG, Guan L, Gether U, Byrne B, Kobilka B, Gellman SH. Nat Methods. 2010; 7:1003-1008. [PubMed: 21037590] r) Selao TT, Branca R, Chae PS, Lehtiö J, Gellman SH, Rasmussen SGF, Nordlund S, Norén A. J Proteome Res. 2011; 10:2703-2714. [PubMed: 21443180] s) Chae PS, Rana RR, Gotfryd K, Rasmussen SGF, Kruse AC, Cho KH, Capaldi S, Carlsso E, Kobilka B, Loland CJ, Gether U, Banerjee S, Byrne B, Lee JK, Gellman SH. Chem Commun. 2013; 49:2287-2289.

9. a) Rasmussen SGF, Choi HJ, Fung JJ, Pardon E, Casarosa P, Chae PS, DeVree BT, Rosenbaum DM, Thian FS, Kobilka TS, Schnapp A, Konetzki I, Sunahara RK, Gellman SH, Pautsch A, Steyaert J, Weis WI, Kobilka BK. Nature. 2011; 469:175-180. [PubMed: 21228869] b) Rosenbaum DM, Zhang C, Lyons J, Holl R, Aragao D, Arlow DH, Rasmussen SGF, Choi HJ, DeVree BT, Sunahara RK, Chae PS, Gellman SH, Dror RO, Shaw DE, Weis WI, Caffrey M, Gmeiner P, Kobilka BK. Nature. 2011; 469:236-240. [PubMed: 21228876] c) Rasmussen SGF, DeVree BT, Zou Y, Kruse AC, Chung KY, Kobilka TS, Thian FS, Chae PS, Pardon E, Calinski D, Mathiesen JM, Shah STA, Lyons JA, Caffrey M, Gellman SH, Steyaert J, Skiniotis G, Weis WI, Sunahara RK, Kobilka BK. Nature. 2011; 477:549-555. [PubMed: 21772288] d) Chung KY, Rasmussen SGF, Liu T, Li S, DeVree BT, Chae PS, Calinski D, Kobilka BK, Woods VL Jr, Sunahara RK. Nature. 2011; 477:611-615. [PubMed: 21956331] e) Westfield GH, Rasmussen SGF, Su M, Dutta S, DeVree BT, Chung KY, Calinski D, Velez-Ruiz G, Oleskie AN, Pardon E, Chae PS, Liu T, Li S, Woods VL Jr, Steyaert J, Kobilka BK, Sunahara RK, Skiniotis G. Proc Natl Acad Sci U S A. 2011; 108:1608616091. [PubMed: 21914848] f) Kruse AC, Hu J, Pan AC, Arlow DH, Rosenbaum DM, Rosemond E, Green HF, Liu T, Chae PS, Dror RO, Shaw DE, Weis WI, Wess J, Kobilka BK. Nature. 2012; 482:552-556. [PubMed: 22358844] g) Haga K, Kruse AC, Asada H, Kobayashi TY, Shiroishi M, Zhang C, Weis WI, Okada T, Kobilka BK, Haga T, Kobayashi T. Nature. 2012; 482:547-551. [PubMed: 22278061] h) Manglik A, Kruse AC, Kobilka TS, Thian FS, Mathiesen JM, Sunahara RK, Pardo L, Weis WI, Kobilka BK, Granier S. Nature. 2012; 485:321-326. [PubMed: 22437502] i) Granier S, Manglik A, Kruse AC, Kobilka TS, Thian FS, Weis WI, Kobilka Brian K. Nature. 2012; 485:400-404. [PubMed: 22596164] j) White JF, Noinaj N, Shibata Y, Love J, Kloss B, Xu F, Gvozdenovic-Jeremic J, Shah P, Shiloach J, Tate CG, Grisshammer R. Nature. 2012; 490:508-513. 
[PubMed: 23051748] k) Kellosalo J, Kajander T, Kogan K, Pokharel K, Goldman A. Science. 2012; 337:473-476. [PubMed: 22837527] 1) Rollauer SE, Tarry MJ, Graham JE, Jääskeläinen M, äger FJ, Johnson S, Krehenbrink M, Liu SM, Lukey MJ, Marcoux J, McDowell MA, Rodriguez F, Roversi P, Stansfeld PJ, Robinson CV, Sansom MS, Palmer T, ögbom MH, Berks BC, Lea SM. Nature. 2012; 492:210-214. [PubMed: 23201679]

10. Lee SC, Bennett BC, Hong WX, Fu Y, Baker KA, Marcoux J, Robinson CV, Ward AB, Halpert JR, Stevens RC, Stout CD, Yeager MJ, Zhang Q. Proc Natl Acad Sci U S A. 2013; 110:E12031211. [PubMed: 23479627]

11. Newstead S, Hobbs J, Jordan D, Carpenter EP, Iwata S. Mol Membr Biol. 2008; 25:631-638. [PubMed: 19023694]

12. a) Hjelmeland LM. Proc Natl Acad Sci USA. 1980; 77:6368-6370. [PubMed: 6935651] b) Hjelmeland LM, Nebert DW, Osborne JC. Anal Biochem. 1983; 130:72-82. [PubMed: 6869811] c) Cladera J, Rigaud J-L, Villaverde J, Dunach M. Eur J Biochem. 1997; 243:798-804. [PubMed: 9057848] d) Chattopadhyay A, Harikumar KG, Kalipatnapu S. Mol Membr Biol. 2002; 19:211220. [PubMed: 12463720]

13. Chattopadhyay A, London E. Anal Biochem. 1984; 139:408-412. [PubMed: 6476378]

14. Laible PD, Kirmaier C, Udawatte CS, Hofman SJ, Holten D, Hanson DK. Biochemistry. 2003; 42:1718-1730. [PubMed: 12578387]

15. Caffrey M, Li D, Dukkipati A. Biochemistry. 2012; 51:6266-6288. [PubMed: 22783824]

16. Cheng Y, Ho DM, Gottlieb CR, Kahne D, Bruck MA. J Am Chem Soc. 1992; 114:7319-7320.

17. a) Ujwal R, Bowie JU. Methods. 2011; 55:337-341. [PubMed: 21982781] b) Whiles JA, Deems R, Vold RR, Dennis EA. Bioorg Chem. 2002; 30:431-442. [PubMed: 12642127] 

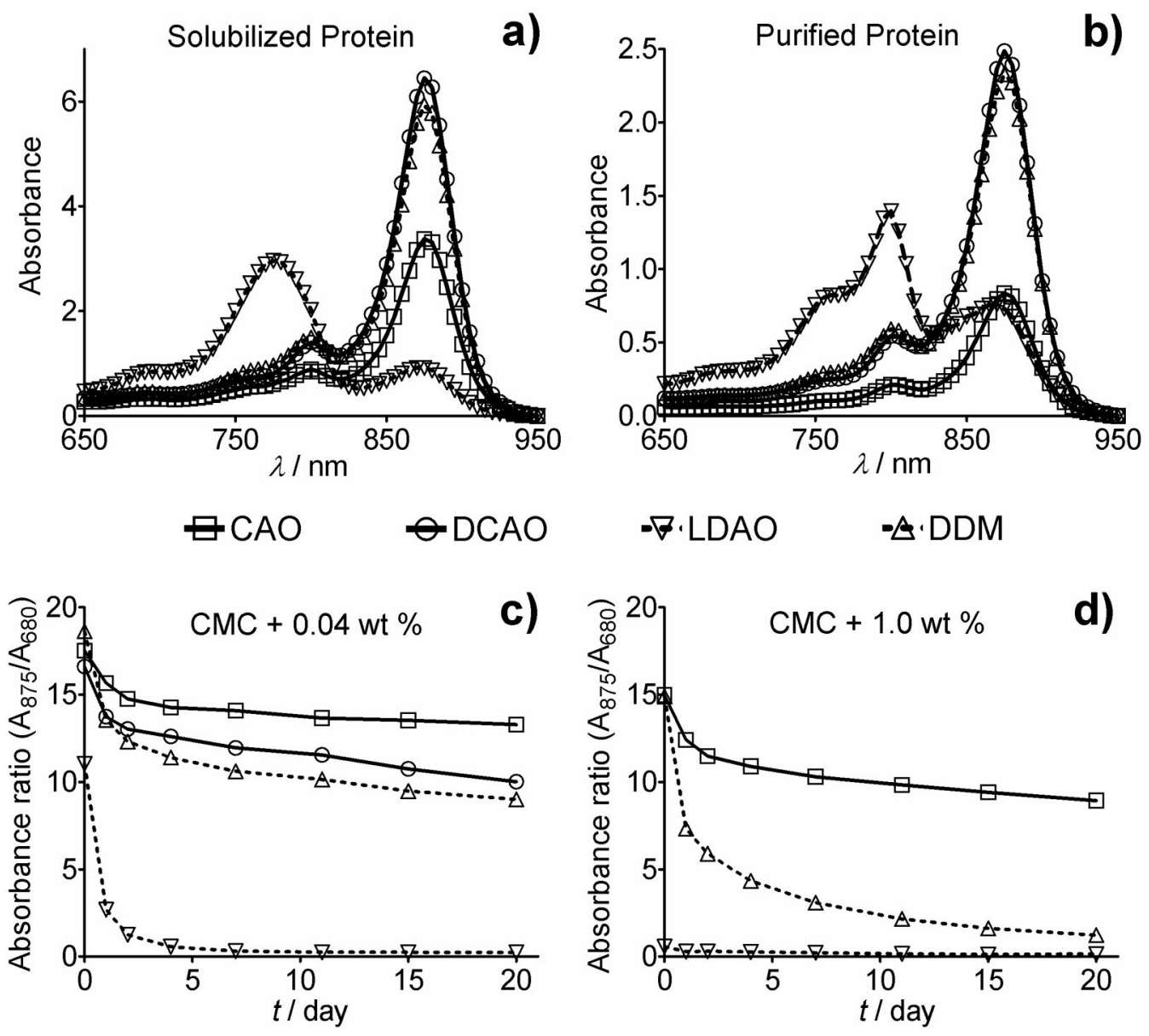

Figure 1.

Absorbance spectra of $R$. capsulatus superassembly (a) solubilized and (b) purified in the new $\mathrm{N}$-oxides (CAO and DCAO) and two conventional detergents (DDM and LDAO). The detergents were used at 2xCMC for CAO, 10xCMC for DCAO, and 50xCMC for DDM and LDAO due to the large variation of their CMC values. For protein purification, we performed Ni-NTA affinity column chromatography and eluted the protein complexes from the resin in a detergent concentration of 1xCMC. Long-term stability of LHI-RC complexes in the individual detergents at (c) $\mathrm{CMC}+0.04 \mathrm{wt} \%$ and (d) $\mathrm{CMC}+1.0 \mathrm{wt} \%$. Protein integrity in each agent was assessed by measuring absorbance ratio $\left(\mathrm{A}_{875} / \mathrm{A}_{680}\right)$ over a 20 day incubation period at room temperature. Each protein sample was dissolved in the binding buffer (10 mM Tris, $\mathrm{pH} 7.8$ and $100 \mathrm{mM} \mathrm{NaCl})$, which was used to purify the protein. 

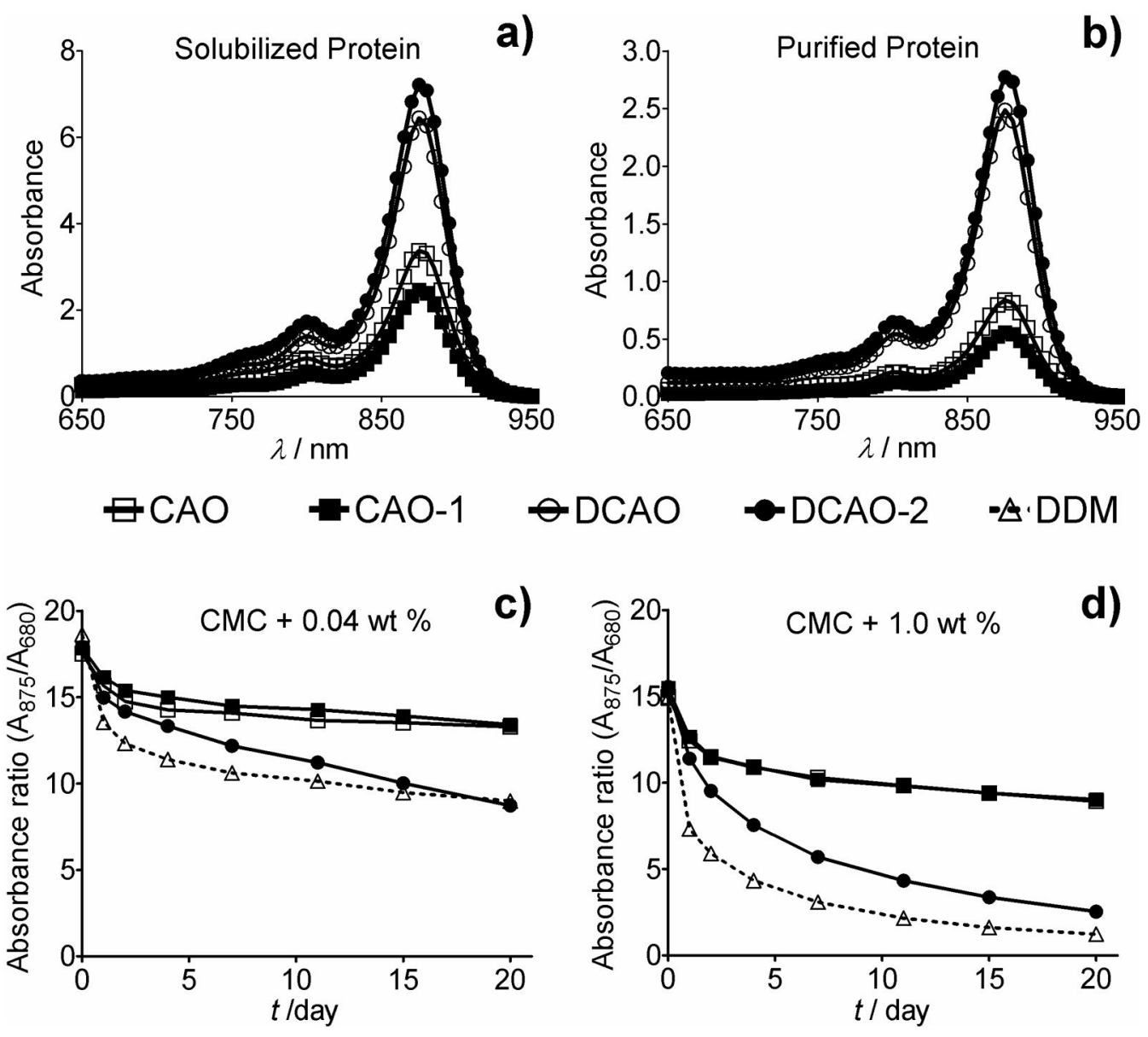

Figure 2.

Absorbance spectra of $R$. capsulatus superassembly (a) solubilized and (b) purified in the new $N$-oxides (CAO, CAO-1, DCAO, and DCAO-2) and a conventional detergent (DDM). The detergents were used at 2xCMC for CAO and CAO-1, and 10xCMC for DCAO and DCAO-2. DDM data were omitted for clarity and can be found in Fig. 1. We purified the protein complexes using a Ni-NTA affinity column and eluted the protein complexes from the resin in a detergent concentration at 1xCMC. Long-term stability of LHI-RC complexes in detergent concentration of (c) $\mathrm{CMC}+0.04 \mathrm{wt} \%$ and (d) $\mathrm{CMC}+1.0 \mathrm{wt} \%$. Protein integrity in each agent was assessed by measuring absorbance ratio $\left(\mathrm{A}_{875} / \mathrm{A}_{680}\right)$ over a 20 day incubation period at room temperature. Each protein sample was dissolved in the binding buffer (10 mM Tris, $\mathrm{pH} 7.8$ and $100 \mathrm{mM} \mathrm{NaCl}$ ), which was used to purify the protein. 

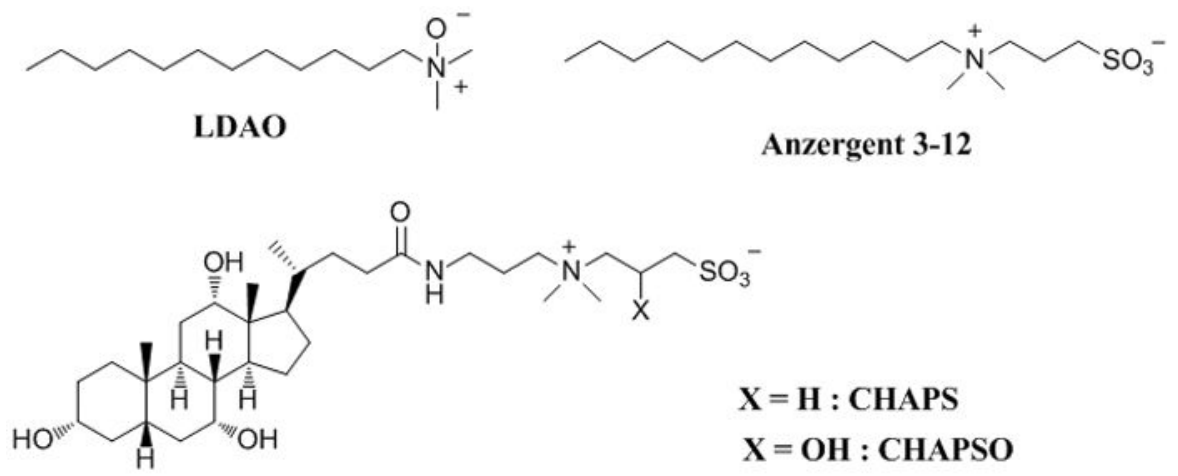

Scheme 1.

Chemical structures of representative zwitterionic detergents (LDAO, Anzergent 3-12, CHAPS, and CHAPSO). 
<smiles>C[N+](C)(C)CCCNC(=O)CC1(C2CCCC2)CCCCCC1</smiles>

DPA-1<smiles>C[N+](C)(C)CCCNC(=O)CC(c1ccccc1)c1ccccc1</smiles>

DPA-2<smiles>C[N+](C)(C)CCCNC(=O)CC(C1CCCCC1)C1CCCCC1</smiles>

DPA-3

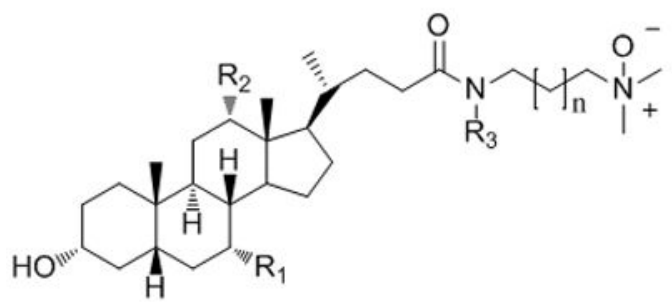

CAO : $\mathbf{R}_{1}=\mathrm{OH}, \mathrm{R}_{2}=\mathrm{OH}, \mathrm{R}_{3}=\mathrm{H}, \mathrm{n}=1$

DCAO : $\mathbf{R}_{1}=\mathbf{H}, \mathbf{R}_{2}=\mathrm{OH}, \mathrm{R}_{3}=\mathrm{H}, \mathrm{n}=\mathbf{1}$

LCAO : $\mathrm{R}_{1}=\mathrm{H}, \mathrm{R}_{2}=\mathrm{H}, \mathrm{R}_{\mathbf{3}}=\mathrm{H}, \mathrm{n}=1$

CAO-1 : $\mathrm{R}_{1}=\mathrm{OH}, \mathrm{R}_{2}=\mathrm{OH}, \mathrm{R}_{3}=\mathrm{CH}_{3}, \mathrm{n}=1$

DCAO-1 : $\mathrm{R}_{1}=\mathrm{H}, \mathrm{R}_{2}=\mathrm{OH}, \mathrm{R}_{3}=\mathrm{CH}_{3}, \mathrm{n}=1$

DCAO-2 : $\mathbf{R}_{1}=\mathrm{H}, \mathrm{R}_{2}=\mathrm{OH}, \mathrm{R}_{3}=\mathrm{CH}_{2} \mathrm{CH}_{3}, \mathrm{n}=\mathbf{0}$

Scheme 2.

Chemical structures of newly synthesized $N$-oxide amphiphiles with hydrophobic variations (DPA-1, DPA-2, DPA-3, CAO, CAO-1, DCAO, DCAO-1, DCAO-2, and LCAO). 


\section{Table 1}

Critical micelle concentrations (CMCs) and protein solubilization yields (SYs) for DPAs (DPA-1, DPA-2, and DPA-3), cholate- and deoxycholate-based $N$-oxide amphiphiles (CAO, CAO-1, DCAO, and DCAO-2) as well as conventional detergents (LDAO and DDM).

\begin{tabular}{ccccc}
\hline & MW $^{[a]}$ & $\mathbf{C M C}(\mathbf{m M})$ & $\mathbf{C M C}(\mathbf{w t} \%)$ & $\mathbf{S Y}(\boldsymbol{\%})^{[\boldsymbol{b}]}$ \\
\hline DPA-1 & 324.5 & $\sim 13$ & $\sim 0.24$ & $\sim 100$ \\
DPA-2 & 326.4 & $\sim 78$ & $\sim 2.5$ & $\sim 15$ \\
DPA-3 & 338.5 & $\sim 4.9$ & $\sim 0.17$ & $\sim 95$ \\
CAO & 508.7 & $\sim 8.3$ & $\sim 0.42$ & $\sim 30$ \\
CAO-1 & 522.8 & $\sim 7.2$ & $\sim 0.36$ & $\sim 20$ \\
DCAO & 492.7 & $\sim 1.3$ & $\sim 0.064$ & $\sim 70$ \\
DCAO-2 & 506.8 & $\sim 1.1$ & $\sim 0.056$ & $\sim 80$ \\
LDAO & 229.4 & $\sim 1.0$ & $\sim 0.023$ & $\sim 100$ \\
DDM & 510.1 & $\sim 0.17$ & 0.0087 & $\sim 70$ \\
\hline
\end{tabular}

${ }^{[a]}$ Molecular weight of detergents.

${ }^{[b]}$ Solubilization yield of LHI-RC complex from the membrane. 